\begin{tabular}{|l|l|l|}
\hline \multicolumn{2}{|c|}{ PublisherInfo } \\
\hline \hline PublisherName & $:$ & BioMed Central \\
\hline \hline PublisherLocation & $:$ & London \\
\hline \hline PublisherImprintName & $:$ & BioMed Central \\
\hline \hline
\end{tabular}

\title{
The usefulness of anaerobic blood cultures
}

\begin{tabular}{|l|l|l||}
\hline \multicolumn{2}{|c|}{ ArticleInfo } \\
\hline \hline ArticleID & $:$ & 4220 \\
\hline \hline ArticleDOI & $:$ & $10.1186 /$ ccf-2000-6239 \\
\hline \hline ArticleCitationID & $:$ & 6239 \\
\hline \hline ArticleSequenceNumber & $:$ & 79 \\
\hline \hline ArticleCategory & $:$ & Paper Report \\
\hline \hline ArticleFirstPage & $:$ & 1 \\
\hline \hline ArticleLastPage & $:$ & 3 \\
\hline \hline & & RegistrationDate : 2000-8-24 \\
\hline ArticleHistory & $:$ & OnlineDate \\
\hline \hline ArticleCopyright & $:$ & Current Science Ltd2000-24 \\
\hline \hline ArticleGrants & $:$ & \\
\hline \hline ArticleContext & $:$ & 1305422 \\
\hline \hline
\end{tabular}


Aff1 Princess Margaret Hospital, Swindon, UK

\section{Keywords}

\section{Comments}

This retrospective review offers reasonable evidence that the routine culturing of anaerobic blood cultures is a waste of time. The incidence of anaerobic bacterial infection is falling. The reasons for this are unknown, although prophylactic antibiotics prior to bowel surgery and the use of broad spectrum antibiotics have been suggested as possible explanations. The authors reviewed all their blood culture data over a three year period. From almost 7000 cultures, only seven had a clinically relevant positive anaerobic result. These were all obvious from clinical examination. The authors suggest that anaerobic blood cultures should only be taken when such an infection is clinically suspected. The problem I have with this paper is that when you look at the cases that the authors suggest are at high risk of anaerobic infection (bowel sepsis, diabetics, severe cardiovascular disease, burns and trauma), these are precisely the populations you see in an ITU. Perhaps blood cultures from ITU patients should be tested routinely for anaerobic bacteraemia, whereas other blood cultures should not.

\section{Introduction}

During the past two decades surveys have shown a reduction in the incidence of anaerobic infections. Possible explanations include the use of prophylactic antibiotics in bowel surgery and the widespread use of broad spectrum antibiotics.

\section{Methods}

This was a retrospective review of all blood cultures analysed by a US hospital microbiology laboratory over a three year period (1994 to 1996 inclusive). 


\section{Results}

Over the three year period, 6891 patient blood cultures were analysed. A total of 1626 patients tested positive for bacterial infection. Aerobic or fungal isolates accounted for 1590 patients. There were 36 anaerobic isolates but 28 of these were the result of contamination. Only seven patients had true anaerobic bacteraemia, all from an obvious source of anaerobic infection which could have been predicted clinically. One patient's data were unavailable for analysis.

\section{References}

1. Ortiz E, Sande MA: Routine use of anaerobic blood cultures: are they still indicated?. Am J Med. 2000, 108: 445-447. 